\title{
Re-Implementation of a Neonatal ICU training program for Respiratory Therapists
}

Kelly Welton, RRT-NPS

\section{"In recent years, in Southern California, two major NICU training courses for Respiratory Therapists have closed their doors. This requires hospitals with NICUs to take on the full responsibility to train their own staff."}

In recent years, in Southern California, two major NICU training courses for Respiratory Therapists have closed their doors. This requires hospitals with NICUs to take on the full responsibility to train their own staff. $\mathrm{NICU}$ is a specialized skill set that requires consistent practice. Annual skills days are not enough. NRP every two years is not nearly enough exposure to all the things RT's and RN's are required to remember in the NICU. In addition, Covid and the staffing demand required every hospital in the US to pull every resource available to concentrate on the needs of the pandemic. Training for anything else took a back seat.

Different hospitals assign their RT staff to NICU according to various guidelines, including staff seniority, Union guidelines, or just plain necessity. For example, some hospitals require all RT's to rotate through all areas of the hospital: ER, PICU, NICU, Adult ICU, and more. Other hospitals allow NICU/Peds RT's to work only with babies and children, no adults. Some hospitals promote staff based on their choice of patient population or responsibility, i.e., an RT can choose a career ladder by expanding their patient type (learn NICU or Pediatrics) or expand their role ( take on supervisory or lead responsibilities).

Different hospitals treat new grads differently. A typical path requires a new grad RT to do 'floor care' for a certain amount of time before being 'promoted' to ICU. This practice makes no sense, as most RT programs' last semester is dedicated entirely to critical care. If they are lucky, students might get to spend one week in a NICU. After graduation, a new RT may express interest in working in the NICU, only to find that they must learn to work the entire rest of the hospital first. Depending on the size of the hospital, the length of time from NICU class in RT school to actual NICU orientation may be years. Many children's hospitals require one year of experience before hiring a new grad. When the day comes, and they are finally offered a NICU orientation, many discover their education and practice (if any) has been severely diminished. Also, consider RT's and RN's who work in adult hospitals who would like to learn a new skill to expand their scope and pursue new career avenues at other hospitals.

The closure of the two NICU course venues prompted me as an
RT Educator to put together every shred of NICU education and skills materials I had. Before Covid eviscerating everything on my calendar for 2020, many students of my live Pediatric RT courses often remarked on the course evaluation, "could I please put on a NICU course?"

In soliciting help from various organizations to put a class together, no one seemed equipped or willing to step forward.

With an initial sketch of what would make good content in mind, I had to prioritize. How many days should the class be? How should the content progress? With these 2 issues solved (5 days' worth of content, start with absolute beginners and move to more complex topics) one question remained: How am I going to talk for five days straight by myself?

I talked up the idea to anyone who would listen: fellow RT's, RN friends, Neonatologists, everyone. Months later, as if by magic, an RT friend from a former employer showed up one day to tell me she had another NICU RT who wanted to help with the class and a medical director interested in helping. If you build it, they will come...... Moreover, build it we did.

\section{"The biggest challenge to presenting online is figuring out how to do an essential part of NICU training: hands-on practice. We were getting our big fingers and hands around the tiniest nasal CPAP mask, securing it in the right place, and giving surfactant without moving the ET tube one millimeter"}

Precisely 18 months later, we went live. Covid had us take a left turn with our live presentation plans, and upload everything online, which proved to be good practice for our content in terms of timing and difficulty level for NICU newbies. The biggest challenge to presenting online is figuring out how to do an essential part of NICU training: hands-on practice. We were getting our big fingers and hands around the tiniest nasal CPAP mask, securing it in the right place, and giving surfactant without moving the ET tube one millimeter. Watching what changing conventional ventilator and HFOV settings will do to waveform graphics and a test lung-securing the ET tube without taping the baby's eyes shut-using a flow-inflating bag for the first time without ending up on +20 of PEEP.

At the end of our first 3-day session, we debriefed on how things went. Evaluations were good. Our timing was only slightly off. We

NEONATOLOGY TODAY is interested in publishing manuscripts from Neonatologists, Fellows, NNPs and those involved in caring for neonates on case studies, research results, hospital news, meeting announcements, and other pertinent topics.

Please submit your manuscript to: LomaLindaPublishingCompany@gmail.com 
did not get to some subjects and needed two more people to staff the hands-on stations. Some topics needed more detail; some could use less detail. This course will probably span four days in the future, given the skill level required in a NICU. However, for a start, we believe we laid a good, solid foundation for the attendees to work with a preceptor (sooner rather than later) and start implementing the ideas and methods they were taught.

Interested in hosting a 3-day Academy of Neonatal Care course? Please contact: Educator@academyofneonatalcare.org..

Disclosures: The author is President of the Academy of Neonatal Care, A Delaware 501 C (3) not for profit corporation.

\section{NT}

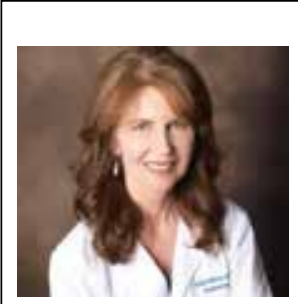

Corresponding Author

Kelly Welton, RRT-NPS

President,

Academy of Neonatal Care

La Quinta, California, United State

www.AcademyofNeonatalCare.org

Phone: 877-884-4587

Email: Educator@academyofneonatalcare.org

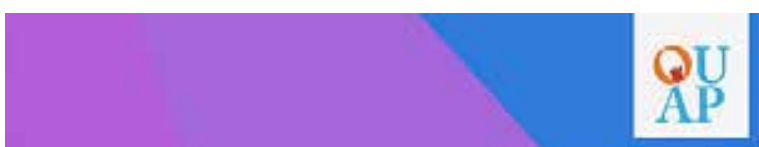

COMING SPRING 2021

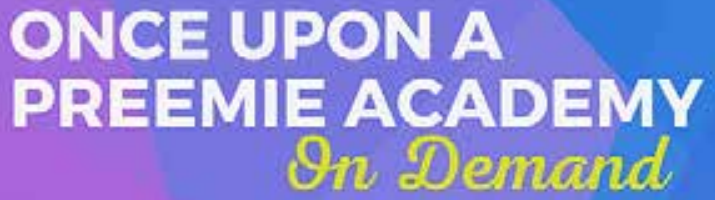

SIGN UP AND GET

Academy updates.

Training news.

YES, SIGN ME UP!

EARN CME/CEU

Learn more, visit

onceuponapreemieacademy.com

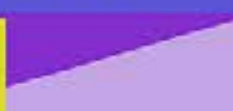

\section{Readers can also follow NEONATOLOGY}

\author{
via our Twitter Feed \\ @NEO
}

\section{New subscribers are always welcome!}

\section{NEONATOLOGY}

To sign up for a free monthly subscription, just click on this box to go directly to our subscription page

\section{Oo National Perinatal Association PERINATAL SUBSTANCE USE}

nationalperinatal.org/position

www.nationalperinatal.org/Substance_Use

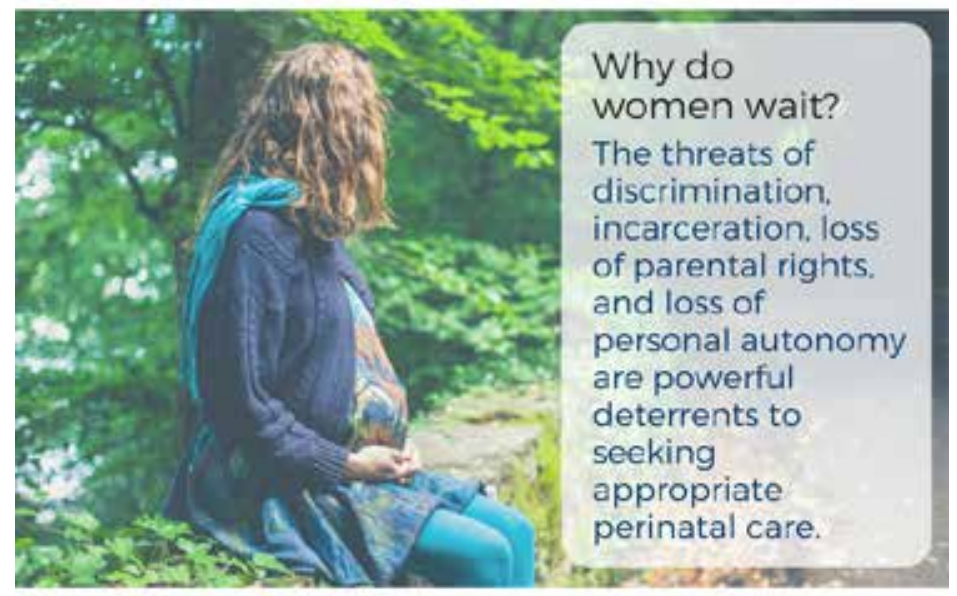

Educate. Advocate. Integrate. 